\title{
Effect of Inhaled Corticosteroids on Glycemic Status
}

\author{
Francis Egbuonu ${ }^{1}$, Farrah A. Antonio ${ }^{1}$ and Mahamood Edavalath ${ }^{* 2}$ \\ ${ }^{I}$ Department of Medicine, University Hospital of North Staffordshire, ST4 6QG, UK \\ ${ }^{2}$ Department of Endocrinology \& Diabetes, University Hospital of North Staffordshire, ST4 6QG, UK
}

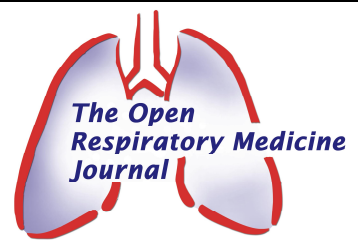

\begin{abstract}
Although the dysglycemic effects of systemic glucocorticoid therapy are well known, the effect of inhaled corticosteroids (ICS) on carbohydrate metabolism is still a subject of debate. The systemic bioavailability of ICS is claimed to be minimal and the side effects negligible. However, some large retrospective cohort studies showed a definite association between ICS use and incident diabetes or worsening glycemic control in pre-existing diabetes. There are no professional-body recommended guidelines on the diagnosis and management of steroid-induced diabetes for the general population. This review aims to evaluate the systemic dysglycemic effect of ICS treatment and to propose a management algorithm.
\end{abstract}

Keywords: Diabetes control, diabetes mellitus, dysglycemic status, hyperglycemia, inhaled corticosteroids (ICS), steroidinduced diabetes.

\section{INTRODUCTION}

Systemic glucocorticoid therapy can lead to various metabolic complications in glucose homeostasis including insulin resistance, hyperglycemia and increased risk of diabetes [1]. In comparison to the oral or parenteral routes of administration, inhaled corticosteroids (ICS) are known to produce relatively less systemic adverse effects and their effect on carbohydrate metabolism is less well recognized.

ICS are considered an integral part of anti-inflammatory treatment in patients with asthma, although their effectiveness in COPD remains controversial [2]. In patients with COPD, the use of ICS is primarily recommended for severe disease and in those with frequent episodes of exacerbations [3]. Nevertheless they are increasingly being used even in patients with less severe disease [4].

Patients with COPD are known to have a higher risk of developing type 2 diabetes [5]. Various underlying factors such as oxidative stress, systemic inflammation, insulin resistance, abnormal adipokine metabolism, and weight gain play major roles in the underlying pathophysiology [6]. In addition, people with diabetes are known to develop significantly more adverse COPD outcomes including increased frequency of exacerbations and recurrent chest infections compared to non diabetics [6].

It is well-known that both COPD and diabetes are associated with an increased risk of cardiovascular mortality. Cardiovascular disease accounts for the most common cause of death in diabetics and the second most common cause in patients with COPD [7]. Diabetes and COPD as comorbidities are on the rise, with an increasing prevalence of both these conditions globally, adding significant complexity

\footnotetext{
*Address correspondence to this author at the Department of Endocrinology, Royal Stoke University Hospital, Stoke-on-Trent, ST4 6QG, UK; E-mail: edmahamood@hotmail.com
}

to the therapeutic measures. The aim of this article is to explore the potential association between ICS treatment and its negative effects on glycemic status, and to discuss the management issues.

\section{EFFECTS OF GLUCOCORTICOIDS ON GLYCEMIC STATUS}

Exogenous administration of glucocorticoids can lead to altered glucose metabolism including hyperglycemia. This can result in either the development of new-onset diabetes or worsening of glycemic control in those who have preexisting diabetes. Some important metabolic adverse effects of corticosteroids and the potential mechanisms are shown in Table 1. Glucocorticoids exert their dysglycemic actions through various mechanisms including decreased insulin production, increased insulin resistance, reduced insulin sensitivity and increased hepatic gluconeogenesis $[1,8]$.

Glucocorticoids cause pancreatic $\beta$-cell dysfunction which results in a marked reduction of insulin secretion [9]. The effects of steroid hormones in the $\beta$-cells are mediated through glucocorticoid receptors (GR) as in other body cells. Stimulation of GR result in alteration of $\beta$-cell metabolism and lead on to a cascade of events such as reduced glucose transport and increased glucose cycling due to increased glucose-6-phophatase activity. The result is a decrease in insulin secretion [9]. Although insulin resistance is considered as a key factor for the development of type 2 diabetes mellitus (T2 DM), the role of $\beta$-cell dysfunction in the development of T2 DM is increasingly being recognized $[10]$. Acute $[11,12]$ and chronic glucocorticoid administration [13] have been shown to reduce $\beta$-cell function and insulin secretion in human beings.

Insulin resistance (IR) is the key component of T2 DM. Glucocorticoids increase insulin resistance by various mechanisms. Skeletal muscles play a key role in glucose 
Table1. Important steroid-related metabolic effects in the body.

\begin{tabular}{|c|c|c|}
\hline Steroid-Related Metabolic Effect & Mechanism & Adverse Consequences \\
\hline \hline Altered carbohydrate metabolism & $\begin{array}{c}\text { Increased gluconeogenesis, reduced glucose } \\
\text { uptake and reduced utilization of glucose } \\
\text { peripherally }\end{array}$ & $\begin{array}{c}\text { Hyperglycemia. In diabetics with limited pancreatic function, } \\
\text { this cannot be compensated by increasing circulating insulin } \\
\text { levels and usually require pharmacological interventions }\end{array}$ \\
\hline Altered protein metabolism & Breakdown of proteins & Muscle weakness \\
\hline Altered lipid metabolism & $\begin{array}{c}\text { Increased lipolysis and ectopic mobilization } \\
\text { of fat }\end{array}$ & $\begin{array}{c}\text { Redistribution of adipose tissues with central obesity and } \\
\text { Cushingoid appearance }\end{array}$ \\
\hline $\begin{array}{c}\text { Altered calcium metabolism and bone } \\
\text { turnover }\end{array}$ & $\begin{array}{c}\text { Reduced calcium uptake in GI tract and } \\
\text { adverse effects on skeletal cells }\end{array}$ & $\begin{array}{c}\text { Osteopenia, osteoporosis and osteonecrosis } \\
\text { Altered fluid and electrolyte balance }\end{array}$ \\
\hline Altered immune function & $\begin{array}{c}\text { Fuppression of inflammatory response } \\
\text { including B cell and T cell function }\end{array}$ & Hypertension and edema \\
\hline
\end{tabular}

metabolism. It utilizes insulin to remove more than $80 \%$ of the postprandial glucose upsurge in the circulation $[13,14]$. The majority of glucose in the body is stored as glycogen in the skeletal muscles. Glucocorticoids impair insulin mediated glucose uptake in muscles and thereby, aggravate skeletal muscle IR [14-17]. Increased muscle catabolism related to chronic steroid administration is also shown to be associated with an increase in IR [14, 18]. Increases in lipolysis and circulating levels of triglycerides (TG) and free fatty acids (FFA) are seen in patients receiving steroids. Excess TG and FFA in circulation has been shown to increase the IR $[19,20]$.

Glucocorticoids alter the hepatic glucose and lipid metabolism by multiple mechanisms. Glucocorticoids increase the endogenous glucose output from the liver [21] by enhancing glycogenolysis [13] and gluconeogenesis [22]. Induction of hepatic insulin resistance directly by decreasing insulin sensitivity [13] and indirectly by increasing FFA and TG supply to the liver [23] are the consequences of chronic glucocorticoid administration. An increase in hepatic glucose output is the net effect of these metabolic alterations related to glucocorticoid therapy that may result in development of frank T2 DM or worsening of pre-existing diabetes.

Chronic glucocorticoid administration has been found to be associated with alteration of body fat composition and distribution. High dose steroid therapy may result in iatrogenic Cushing syndrome (CS). Ectopic distribution of fat that results in central obesity is one of the pathological hallmarks of CS. Body fat redistribution with excess visceral and abdominal fat, and reduced peripheral fat is seen in patients on chronic corticosteroid therapy [24] even without the development of frank CS. Several hormones from the adipose tissues such as leptin, resistin and adiponectin control insulin signaling and IR in human beings. Alterations in these hormones induced by chronic steroid treatment can therefore aggravate dysglycemia in patients.

\section{CLINICAL PRESENTATION OF GLUCOCORTICOID- INDUCED DYSGLYCEMIA}

Glucocorticoid therapy is the most common cause of drug-induced diabetes [25]. Although, the exact figures are unknown, a prevalence of post-prandial hyperglycemia of up to $42 \%$ has been reported in non-diabetic patients on moderate doses of oral steroid treatment [25, 26]. Many patients on low to moderate doses of glucocorticoid treatment may only have hyperglycemia without symptoms of frank diabetes. However, frank T2 DM develops in a significant proportion of patients who are on large doses of steroids especially while on long-term treatment [25]. In patients with established diabetes (whether type 1 or type 2), the use of glucocorticoid therapy can result in worsening glycemic control even on short courses [25, 27]. Diabetic emergencies such as ketoacidosis [28] and hyperosmolar hyperglycemic state [29] are the other dysglycemic complications associated with glucocorticoid therapy.

Studies showed that the glycemic rise related to steroid therapy usually begins 4 hours after the dose and usually persists for up to 16 hours $[25,30]$. Therefore, conventional testing methods to diagnose diabetes may not be appropriate in steroid-induced diabetes. Fasting hyperglycemia may not be evident in many cases and only postprandial hyperglycemia is seen in most patients. There are no formal guidelines on the diagnosis and management of steroidinduced diabetes and dysglycemic state from international bodies. (except for transplant-related diabetes, for which management is similar to T2 DM [31]) Hence, the diagnosis and management of these cases should be individualized according to the clinical situation.

A random blood glucose level of $\geq 200 \mathrm{mg} / \mathrm{dL}(\geq 11.1$ $\mathrm{mmol} / \mathrm{L})$ with classic symptoms of hyperglycemia or a glucose level of $\geq 200 \mathrm{mg} / \mathrm{dL}$ at 2 hours after a 75 -g glucose tolerance test was proposed as reasonable diagnostic tests for glucocorticoid-induced diabetes [25]. The random blood glucose check is preferably done in the afternoon (as most patients on chronic steroid therapy receive the dose in the morning) or two hours post-meal. Although less sensitive, a fasting blood glucose $\geq 126 \mathrm{mg} / \mathrm{dL}(\geq 7.0 \mathrm{mmol} / \mathrm{L})$ or $\mathrm{HbA} 1 \mathrm{c}$ $\geq 6.5 \%(\geq 48 \mathrm{mmol} / \mathrm{mol})$ in a symptomatic patient (or repeatedly elevated levels in an asymptomatic case) can also be used as a diagnostic test [25].

\section{ICS AND DYSGLYCEMIA}

ICS are usually prescribed for the management of obstructive airways diseases, asthma and COPD; the world health organization (WHO) estimates a global disease burden of 235 and 64 million respectively [32]. The systemic bio- 
availability of ICS is claimed to be minimal and therefore, the metabolic complications related to ICS use is expected to be negligible. However, the systemic bioavailability depends on the type of molecule, the mode of administration, daily dosage, and the pharmacokinetic and pharmacodynamic properties of ICS drug molecule.

Despite developing various inhalation devices to improve locally targeted delivery of drugs in the airways, significant proportion of ICS can still reach the systemic circulation especially at high doses. ICS may enter the systemic circulation either through lungs or gastrointestinal tract. It is estimated around 10 to $40 \%$ of inhaled medications actually make it to the desired location in the airways. The rest is swallowed and reaches gastrointestinal tract [33]. However, only a small amount of this actually reaches systemic circulation since majority of the swallowed dose undergoes first pass metabolism in the liver. In addition, after exerting its desired effect in the airways the ICS eventually get absorbed systemically resulting in further extra-pulmonary effects [34].

It is well established that long-term ICS use causes a number of dose-dependent side effects including adrenal suppression, reduction in bone density, ocular hypertension, posterior sub-capsular cataracts and reduction of growth velocity $[35,36]$. In view of the overwhelming evidence of systemic side effects with ICS therapy, various studies have attempted to explore its dysglycemic effects and to date there have been mixed results. As early as in 1998, it was reported that a patient with T2 DM and asthma developed persistent glycosuria and a significant (1 percent) increase in glycated hemoglobin (HbAlc) with higher doses of inhaled fluticasone (2000 mcg/day) [37].

In a prospective cohort study involving 1698 subjects [38], it was observed that the use of ICS was associated with a dose-dependent increase in serum glucose levels in patients known to have diabetes. This study showed that for every additional $100 \mu \mathrm{g}$ of inhaled Triamcinolone used (or equivalent), there was a $1.82 \mathrm{mg} / \mathrm{dL}$ rise in plasma glucose concentration in patients with COPD and pre-existing diabetes. However, such effects with glycaemic control were not observed among patients without a history of diabetes.

A small prospective randomized, double-blind placebocontrolled study [39], reported a statistically significant difference in self-measured blood glucose in diabetics with either COPD or asthma following ICS therapy with fluticasone $440 \mathrm{mcg}$ twice daily. However, the study failed to demonstrate a statistically significant change in $\mathrm{HbAlc}$ levels. It is possible that the short study duration (42 days) could have lead to an underestimation of the effect of ICS on HbA1c. O'Byrne and colleagues, in a retrospective analysis of various clinical trials, failed to demonstrate any increased risk of new onset diabetes or hyperglycemia with the use of ICS in patients with asthma or COPD [40]. The short duration of the follow up and the lack of biochemical validation of diabetes are notable limitations of this study. In addition, patients enrolled in this analysis were largely without any other significant co-morbidities. Therefore, it will be difficult to extrapolate the results of this study to determine the long-term dysglycemic effects of ICS therapy in diabetics with multiple co-morbidities.
In another study among uncontrolled asthmatics, high dose ICS therapy was noted to improve glucose tolerance and decrease the IR during the early phase of the follow up [41]. It is well-known that unstable asthma is associated with increased endogenous catecholamine production due to the physical stress which can have an effect on the glycemic parameters. Therefore, the favorable glycemic effect noted during the early phase of treatment could be due to the reduction of endogenous catecholamines resulting from the resolution of unstable asthma rather than the ICS therapy.

A large retrospective cohort study identified that the patients treated with ICS for COPD or asthma over a period of 5.5 years were associated with a statistically significant $34 \%$ increase in the rate of developing diabetes and diabetes progression compared with patients not treated with ICS [42]. In this study, of the 388,584 patients, 30,167 were diagnosed with new onset diabetes during the follow up period (an incidence of 14.2/ 1000/ year) and 2099 subsequently progressed to insulin from oral anti-diabetic treatment (an incidence of 19.8/ 1000/ year). It is also noted that the risk of developing diabetes is more pronounced at the higher dose of ICS therapy. However, it should be borne in mind that any chronic systemic disease like COPD is associated with increased IR which can result in worsening dysglycemia [43]. Patients on ICS are more likely to have had more severe disease that may heavily bias the results of this study. Use of rescue systemic steroids for exacerbations of the disease is also higher among patients with poorly controlled asthma or COPD. This may further complicate the interpretation of such retrospective studies.

An association between chronic respiratory diseases and diabetes has been proposed by some investigators [7, 43-45]. Chronic illnesses result in a systemic inflammatory state associated with increase in IR. This invariably causes a dysglycemic state in prone individuals and worsening of glycemic control in patients with diabetes. Poor control of asthma was found to be associated with worse glycemic control in the young type 1 diabetes patients [46]. The overall benefits and risks associated with ICS use definitely favors the use in patients with persistent asthma, and all professional bodies agree on this treatment at optimal dosage necessary for proper control of the disease. However, there is still uncertainty about the benefits in patients with COPD.

\section{MANAGEMENT OF DIABETES IN ICS USERS}

There are no formal guidelines specific to the management of diabetes in ICS users especially with the lack of robust evidence on the definite association. However, it will pose a therapeutic challenge to manage the potential dysglycemic effect of ICS in clinical practice, considering the high prevalence of diabetes and chronic respiratory illnesses in the general population

A diagnostic and management algorithm for steroidinduced diabetes has been proposed by Lansang and Hustak of the Cleveland Clinic in 2011 [25]. In the absence of formal professional body guidelines, it would be appropriate to rely upon these recommendations to manage patients with ICS-induced dysglycemia. Life style measures like regular exercise may not always be practical for glycemic control in patients with asthma and COPD as their respiratory disease 
Table 2. Management algorithm for steroid-induced diabetes [25] (DPP4 = dipeptidyl peptidase; GLP-1 = glucogon-like protein-1).

\begin{tabular}{|c|c|}
\hline Random or 1- to 2-Hour Post-Meal Glucose & Medication/Medication Class \\
\hline \hline$<220 \mathrm{mg} / \mathrm{dL}(12.2 \mathrm{mmol} / \mathrm{L})$ & $\begin{array}{c}\text { Metformin or DPP4-inhibitor (different gliptins) or meglitinides (e.g., repaglinide, nataglinide) or GLP- } \\
1 \text { agonists (e.g., exenatide, liraglutide) or sulphonylureas (e.g., gliclazide, glipizide, glyburide) }\end{array}$ \\
\hline $220-300 \mathrm{mg} / \mathrm{dL}(12.2-16.7 \mathrm{mmol} / \mathrm{L})$ & $\begin{array}{c}\text { Start with single agent and if not controlled within 2-3 months add one of the second group of } \\
\text { medication mentioned above or insulin }\end{array}$ \\
\hline$>300 \mathrm{mg} / \mathrm{dL}(>16.7 \mathrm{mmol} / \mathrm{L})$ & $\begin{array}{c}\text { Insulin is mostly required especially in those with hyperglycemic symptoms. Addition of an appropriate } \\
\text { oral agent may reduce the insulin dose requirement }\end{array}$ \\
\hline
\end{tabular}

may impose restrictions on such modalities of treatment. They propose a stepwise algorithm for glycemic control in steroid-induced diabetes with consideration of random or 1to 2-hour post-meal plasma glucose readings [25]. The management algorithm is shown in the Table 2.

Insulin when required for the control of hyperglycemia, can be started as a pre-mixed formulation (long acting to short acting molar ratio of 70:30 or 50:50) according to the glycemic levels and follow up with capillary glucose checking. A starting insulin dose of $0.15-0.3$ units/ kg body weight is reasonable [25]. Although post-meal capillary glucose checking is ideal, it may not always be practical. Pre-meal glucose checks shall give the overall glycemic fluctuations throughout the day that is helpful for adjusting the insulin doses. Glycemic targets of 70-130 mg/ dL (3.9$7.2 \mathrm{mmol} / \mathrm{L})$ before meals and $<180 \mathrm{mg} / \mathrm{dL}(<10 \mathrm{mmol} / \mathrm{L})$ post-meal are reasonable [25]. Patients with T1 DM on continuous subcutaneous insulin infusion (CSII) pumps while on short course steroid therapy were found to benefit from data recorded by continuous glucose monitors (CGMS) for insulin dose titrations [47]. CGMS data may be also useful in T1 DM patients on CSII pumps for titration of the insulin regime if the glycemic control becomes erratic while of ICS treatment.

\section{CONCLUSION}

There are mixed data as to the effect of ICS on glucose metabolism in both diabetic and non-diabetic individuals. Some studies have clearly demonstrated that ICS treatment can produce systemic side effects including derangement of glucose metabolism. However, other studies failed to demonstrate clinically significant adverse dysglycemic effects of ICS treatment. Failure to demonstrate adverse metabolic outcomes in some of these studies could be due to the relatively small number of participants and short durations of follow up. The largest population-based study showed an increased risk of development and progression of diabetes among patients on ICS therapy. Therefore it is prudent to assess any possible interaction between ICS use and deterioration in glycemic control by careful monitoring. Large-scale prospective controlled studies are necessary to address this issue.

Steroid-induced dysglycemia often presents with postmeal and daytime hyperglycemia, although fasting hyperglycemia is also observed in a significant proportion of cases. In the absence of formal guidelines for diagnostic evaluation and management of steroid-induced dysglycemia, the algorithm proposed in this paper could be used for the management of ICS-related dysglycemic state.

\section{CONFLICT OF INTEREST}

The authors confirm that this article content has no conflict of interest.

\section{ACKNOWLEDGEMENTS}

Declared none.

\section{REFERENCES}

[1] Schäcke H, Döcke WD, Asadullah K. Mechanisms involved in the side effects of glucocorticoids. Pharmacol Ther 2002; 96: 23-43.

[2] Suissa S, Barnes PJ. Inhaled corticosteroids in COPD: the case against. Eur Respir J 2009; 34: 13-6.

[3] De Coster DA, Jones M. Tailoring of corticosteroids in COPD management. Curr Respir Care Rep 2014; 3: 121-32.

[4] Corrado A, Rossi A. How far is real life from COPD therapy guidelines? An Italian observational study. Respir Med 2012; 106 : 989-97

[5] Rana JS, Mittleman MA, Sheikh J, et al. Chronic obstructive pulmonary disease, asthma, and risk of type 2 diabetes in women. Diabetes Care 2004; $27:$ 2478-84.

[6] Mirrakhimov AE. Chronic obstructive pulmonary disease and glucose metabolism: a bitter sweet symphony. Cardiovasc Diabetol 2012; 11: 132

[7] Martinez-Ceron E, Barquiel B, Pallardo LF, Alvarez-Sala R. Chronic Obstructive Pulmonary Disease and Diabetes Mellitus. In: Kian-Chung Ong, Ed.. Chronic Obstructive Pulmonary Disease Current Concepts and Practice (2012). Available from: http://www.intechopen.com/books/chronic-obstructive-pulmonarydisease-current-concepts-and-practice/chronic-obstructivepulmonary-disease-and-diabetes-mellitus [Accessed on 29 May 2014].

[8] Andrews RC, Walker BR. Glucocorticoids and insulin resistance: old hormones, new targets. Clin Sci (Lond) 1999; 96: 513-23.

[9] Lambillotte C, Gilon P, Henquin JC. Direct glucocorticoid inhibition of insulin secretion. An in vitro study of dexamethasone effects in mouse islets. J Clin Invest 1997; 99: 414-23.

[10] Kahn SE. The relative contributions of insulin resistance and betacell dysfunction to the pathophysiology of Type 2 diabetes. Diabetologia 2003; 46: 3-19.

[11] Shamoon H, Soman V, Sherwin RS. The influence of acute physiological increments of cortisol on fuel metabolism and insulin binding to monocytes in normal humans. J Clin Endocrinol Metab 1980; 50: 495-501.

[12] Kalhan SC, Adam PA. Inhibitory effect of prednisone on insulin secretion in man: model for duplication of blood glucose concentration. J Clin Endocrinol Metab 1975; 41: 600-10.

[13] van Raalte DH, Ouwens DM, Diamant M. Novel insights into glucocorticoid-mediated diabetogenic effects: towards expansion of therapeutic options? Eur J Clin Invest 2009; 39: 81-93.

[14] Defronzo RA, Jacot E, Jequier E, Maeder E, Wahren J, Felber JP The effect of insulin on the disposal of intravenous glucose. Results from indirect calorimetry and hepatic and femoral venous catheterization. Diabetes 1981; 30: 1000-7. 
[15] Long W, Barrett EJ, Wei L, Liu Z. Adrenalectomy enhances the insulin sensitivity of muscle protein synthesis. Am J Physiol Endocrinol Metab 2003; 284: E102-9.

[16] Ruzzin J, Wagman AS, Jensen J. Glucocorticoid-induced insulin resistance in skeletal muscles: defects in insulin signalling and the effects of a selective glycogen synthase kinase-3 inhibitor. Diabetologia 2005; 48: 2119-30.

[17] Weinstein SP, Wilson CM, Pritsker A, Cushman SW. Dexamethasone inhibits insulin-stimulated recruitment of GLUT4 to the cell surface in rat skeletal muscle. Metabolism 1998; 47: 3-6.

[18] Krebs M, Krssak M, Bernroider E, et al. Mechanism of amino acidinduced skeletal muscle insulin resistance in humans. Diabetes 2002; 51: 599-605.

[19] Perseghin G, Petersen K, Shulman GI. Cellular mechanism of insulin resistance: potential links with inflammation. Int $\mathrm{J}$ Obes Relat Metab Disord 2003; 27(Suppl. 3): S6-11.

[20] Boden G, Shulman GI. Free fatty acids in obesity and type 2 diabetes: defining their role in the development of insulin resistance and beta-cell dysfunction. Eur J Clin Invest 2002; 32(Suppl 3): 14-23.

[21] Vegiopoulos A, Herzig S. Glucocorticoids, metabolism and metabolic diseases. Mol Cell Endocrinol 2007; 275: 43-61.

[22] Kraus-Friedmann N. Hormonal regulation of hepatic gluconeogenesis. Physiol Rev 1984; 64: 170-259.

[23] Parekh S, Anania FA. Abnormal lipid and glucose metabolism in obesity: implications for nonalcoholic fatty liver disease. Gastroenterology 2007; 132: 2191-207.

[24] Morton NM, Seckl JR. 11beta-hydroxysteroid dehydrogenase type 1 and obesity. Front Horm Res 2008; 36: 146-64.

[25] Lansang MC, Hustak LK. Glucocorticoid-induced diabetes and adrenal suppression: how to detect and manage them. Cleve Clin J Med. 2011; 78: 748-56.

[26] Uzu T, Harada T, Sakaguchi M, et al. Glucocorticoid-induced diabetes mellitus: prevalence and risk factors in primary renal diseases. Nephron Clin Pract 2007; 105: c54-7.

[27] Bevier WC, Zisser HC, Jovanovic L, et al. Use of continuous glucose monitoring to estimate insulin requirements in patients with type 1 diabetes mellitus during a short course of prednisone. $\mathbf{J}$ Diabetes Sci Technol 2008; 2: 578-83.

[28] Cagdas DN, Paç FA, Cakal E. Glucocorticoid-induced diabetic ketoacidosis in acute rheumatic fever. J Cardiovasc Pharmacol Ther 2008; 13: 298-300.

[29] Yang JY, Cui XL, He XJ. Non-ketotic hyperosmolar coma complicating steroid treatment in childhood nephrosis. Pediatr Nephrol 1995; 9: 621-22.

[30] Burt MG, Roberts GW, Aguilar-Loza NR, Frith P, Stranks SN. Continuous monitoring of circadian glycemic patterns in patients receiving prednisolone for COPD. J Clin Endocrinol Metab 2011; 96: 1789-96.

[31] Davidson J, Wilkinson A, Dantal J, et al. International Expert Panel. New-onset diabetes after transplantation: 2003 international consensus guidelines. Proceedings of an international expert panel meeting. Barcelona, Spain, 19 February 2003. Transplantation 2003; 75(Suppl 10): SS3-24.

[32] World Health Organization. Chronic respiratory diseases 2011. Geneva: World Health Organization. http://www.who.int/respira tory/about topic/en/ Accessed on 02 June 2014.

[33] Allen DB, Bielory L, Derendorf H, et al. Inhaled corticosteroids: past lessons and future issues. J Allergy Clin Immunol 2003; 112(3 Suppl): S1-40.

[34] Pedersen S, O'Byrne PM. A comparison of the efficacy and safety of inhaled corticosteroids in asthma. Allergy 1997; 52(Suppl 39): $1-34$.

[35] Lipworth BJ. Systemic adverse effects of inhaled corticosteroid therapy: A systematic review and meta-analysis. Arch Intern Med 1999; 159: 941-55.

[36] Rossi GA, Cerasoli F, Cazzola M. Safety of inhaled corticosteroids: room for improvement. Pulm Pharmacol Ther 2007; 20: 23-35.

[37] Faul JL, Tormey W, Tormey V, Burke C. High dose inhaled corticosteroids and dose dependent loss of diabetic control. BMJ 1998; 317(7171): 1491.

[38] Slatore CG, Bryson CL, Au DH. The association of inhaled corticosteroid use with serum glucose concentration in a large cohort. Am J Med 2009; 122: 472-8.

[39] Faul JL, Wilson SR, Chu JW, Canfield J, Kuschner WG. The effect of an inhaled corticosteroid on glucose control in type 2 diabetes. Clin Med Res 2009; 7: 14-20.

[40] O'Byrne PM, Rennard S, Gerstein H, et al. Risk of new onset diabetes mellitus in patients with asthma or COPD taking inhaled corticosteroids. Respir Med 2012; 106: 1487-93.

[41] Kiviranta K, Turpeinen M. Effect of eight months of inhaled beclomethasone dipropionate and budesonide on carbohydrate metabolism in adults with asthma. Thorax 1993; 48: 974-8.

[42] Suissa S, Kezouh A, Ernst P. Inhaled corticosteroids and the risks of diabetes onset and progression. Am J Med 2010; 123: 1001-6.

[43] Mirrakhimov AE. Chronic obstructive pulmonary disease and glucose metabolism: a bitter sweet symphony. Cardiovasc Diabetol 2012; 11: 132.

[44] Yun HD, Knoebel E, Fenta Y, et al. Asthma and proinflammatory conditions: a population-based retrospective matched cohort study. Mayo Clin Proc 2012; 87: 953-60.

[45] Mannino DM, Thorn D, Swensen A, Holguin F. Prevalence and outcomes of diabetes, hypertension and cardiovascular disease in COPD. Eur Respir J 2008; 32: 962-9.

[46] Black MH, Anderson A, Bell RA, et al. Prevalence of asthma and its association with glycemic control among youth with diabetes. Pediatrics 2011; 128: e839-47.

[47] Bevier WC, Zisser HC, Jovanovic L, et al. Use of continuous glucose monitoring to estimate insulin requirements in patients with type 1 diabetes mellitus during a short course of prednisone. J Diabetes Sci Technol 2008; 2: 578-83. 